University of Nebraska - Lincoln

DigitalCommons@University of Nebraska - Lincoln

$12-15-2008$

\title{
Use of a candidate gene array to delineate gene expression patterns in cattle selected for resistance or susceptibility to intestinal nematodes
}

Ricardo N. Araujo

Terezinha Padilha

Dante Zarlenga

Tad Sonstegard

Erin E. Connor

See next page for additional authors

Follow this and additional works at: https://digitalcommons.unl.edu/usdaarsfacpub

This Article is brought to you for free and open access by the U.S. Department of Agriculture: Agricultural Research Service, Lincoln, Nebraska at DigitalCommons@University of Nebraska - Lincoln. It has been accepted for inclusion in Publications from USDA-ARS / UNL Faculty by an authorized administrator of DigitalCommons@University of Nebraska - Lincoln. 


\section{Authors}

Ricardo N. Araujo, Terezinha Padilha, Dante Zarlenga, Tad Sonstegard, Erin E. Connor, Curt Van Tassel, Walter S. Lima, Evaldo Nascimento, and Louis C. Gasbarre 


\title{
Use of a candidate gene array to delineate gene expression patterns in cattle selected for resistance or susceptibility to intestinal nematodes
}

\author{
Ricardo N. Araujo a,b, Terezinha Padilha ${ }^{c}$, Dante Zarlenga ${ }^{\mathrm{a}}$, Tad Sonstegard ${ }^{\mathrm{a}}$, Erin E. Connor ${ }^{\mathrm{a}}$, \\ Curt Van Tassel $^{\mathrm{a}}$, Walter S. Lima ${ }^{\mathrm{b}}$, Evaldo Nascimento ${ }^{\mathrm{b}}$, Louis C. Gasbarre ${ }^{\mathrm{a}, *}$ \\ ${ }^{\text {a } U S D A, ~ A R S, ~ B o v i n e ~ F u n c t i o n a l ~ G e n o m i c s ~ L a b o r a t o r y, ~ B e l t s v i l l e, ~ M D, ~ U S A ~}$ \\ ${ }^{\mathrm{b}}$ Parasitology Department, Federal University of Minas Gerais, Belo Horizonte, MG, Brazil \\ ${ }^{\mathrm{c}}$ EMBRAPA LABEX, Beltsville, MD, United States
}

\section{A R T I C L E I N F O}

\section{Article history:}

Received 31 March 2008

Received in revised form 12 December 2008

Accepted 15 December 2008

\section{Keywords:}

Nematodes

Microarray

Cooperia

Immune response

Cattle

\begin{abstract}
A B S T R A C T
In the present study, we use microarray technology to investigate the expression patterns of 381 genes with known association to host immune responses. Hybridization targets were derived from previously characterized bovine cDNAs. A total of 576 reporters (473 sequence-validated cDNAs and 77 controls) were spotted onto glass slides in two sets of four replicates. Two color, comparative hybridizations across both mesenteric lymph node (MLN) and small intestine mucosa (SIM) RNA samples were done between animals with previously demonstrated phenotypic differences based on natural exposure to gastrointestinal (GI) nematodes over a 6-month exposure period. A total of 138 significant hybridization differences were detected by mixed model analysis of variance. A subset of these significant differences was validated by quantitative, real-time RT-PCR to assay transcript levels for 18 genes. These results confirmed that in the SIM, susceptible animals showed significantly higher levels in the genes encoding IGHG1, CD3E, ACTB, IRF1, CCL5 and $\mathrm{C} 3$, while in the MLN of resistant animals, higher levels of expression were confirmed for PTPRC, CD1D and ITGA4. Combined, the results indicate that immune responses against GI nematode infections involve multiple response pathways. Higher levels of expression for IgE receptor, integrins, complement, monocyte/macrophage and tissue factors are related to resistance. In contrast, higher levels of expression for immunoglobulin chains and TCRs are related to susceptibility. Identification of these genes provides a framework to better understand the genetic variation underlying parasite resistance.
\end{abstract}

(c) 2009 Published by Elsevier B.V.

\section{Introduction}

Infection of the bovine gut with gastrointestinal (GI) nematodes remains an economically important health concern of cattle throughout the world. Cooperia oncophora and Ostertagia ostertagi are the most prevalent parasite

\footnotetext{
* Corresponding author at: USDA, ARS, ANRI, BFGL, Bldg 200, Rm 8, BARC-East, Beltsville, MD 20705, USA. Tel.: +1 301504 8509; fax: +1 3015046426

E-mail address: lgasbarr@anri.barc.usda.gov (L.C. Gasbarre).
}

species in temperate regions (Malczewski et al., 1996) Control of these parasites has been based principally on the repeated use of anthelmintics (Williams, 1997). Although these drugs have high efficacy, the various methods of application have generated concern over residues in the environment that contaminate the food supply and increase the appearance of drug resistant parasites (Balic et al., 2000). One approach to reduce anthelmintic use relies on identifying host genetic variation affecting genes or immune response pathways critical to defense. Studies on the distribution of GI nematodes within cattle herds indicated that host genetics plays an important role in 
determining the immune state of the individual (Gasbarre et al., 2001). While the majority of calves on pasture successfully regulate GI nematode infections after sufficient exposure time, a percentage of individuals demonstrate no such ability (Genchi et al., 1989; Gasbarre et al., 1990). This pattern strongly suggests that strategic management of susceptible animals in a herd could considerably reduce overall parasite transmission. Reduced parasite transmission would improve overall animal health, decrease the frequency of pharmaceutical intervention, and alleviate some of the estimated $\$ 2$ billion per year in economic losses in the U.S. caused by increased production costs and lost productivity (Gasbarre, 1997).

To better understand the genetic mechanisms underlying parasite resistance and susceptibility, basic knowledge on the types of immune responses elicited by GI nematode infection must be identified and elucidated. Microarrays provide a platform well suited for studying the transcriptional activity related to parasite infection by providing important information on altered gene expression. In humans and mice, microarrays have been used successfully to monitor changes in gene expression in several studies, including cancer and other diseases (Muhle et al., 2001). Recently, microarray technology has been used for the identification of genes and patterns of gene expression related to nematode resistance in sheep (Diez-Tascón et al., 2005; Keane et al., 2006). In this study, we report the development of a focused bovine cDNA microarray containing gene targets predominantly associated with the host immune system or immunologically mediated responses. These arrays, combined with quantitative, real-time RT-PCR, were then used to define differences in gene expression between cattle phenotypically determined to be either resistant or susceptible to GI nematode infection.

\section{Material and methods}

\subsection{Animals}

Tissue samples for gene expression analyses were obtained from eight Angus yearlings selected from a resource population segregating for traits involved in resistance and susceptibility to GI nematodes (Gasbarre et al., 2001). The mating decisions used to generate this population over the past 15 years were based on measurement of over 50 traits during a natural infection trial period. Data for these traits has been collected for over 300 animals, which has led to a robust assessment of phenotypically distinct animals based upon trial infection results. Briefly, cow-calf pairs were kept on pastures harboring very low numbers of parasites until the median age of the cohort was 205 days. For the trial period after weaning, calves were placed on pastures for natural exposure to trichostrongyle nematode parasites (Ostertagia, Cooperia and Nematodirus spp.). The calves were monitored weekly for a number of parasitological and immunological parameters (Gasbarre et al., 2001), including eggs per gram counts (EPG) (Herlich, 1976). After approximately 6 months on these pastures, the animals were sacrificed for collection of tissue samples and determination of parasite levels. These data (i.e. weekly measurements of EPG), plus data collected at slaughter were used to classify the cattle as resistant or susceptible to parasite infection.

\subsection{Tissue samples and parasite enumeration}

Tissue samples were derived from four animals (two males and two females in each group) of each phenotypic group previously determined by EPG. At slaughter, the small intestine was opened longitudinally to collect the contents through washing with warm water combined with gentle rubbing of the luminal surfaces. An aliquot consisting of $20 \%$ of the wash was fixed in 5\% formalin. For parasite counting and identification, $10 \%$ of the formalin fixed samples (i.e. $2 \%$ of total content of small intestine) was examined microscopically for parasites. Tissue samples from the small intestine mucosa (SIM) and mesenteric lymph node (MLN) were collected in ice-cold calciummagnesium-free Hanks' balanced salt solution (HBSS), disrupted in guanidinium isothiocyanate (4 M guanidinium isothiocyanate, $5 \mathrm{mM}$ Na citrate, $10 \mathrm{mM}$ EDTA, $0.5 \%$ Na sarkosyl, $100 \mathrm{mM} 2$ mercaptoethanol) and stored at $-80{ }^{\circ} \mathrm{C}$.

\subsection{Microarray production}

The reporter cDNA for arraying onto slides was selected based on gene annotation for involvement in the immune system and/or immunologically mediated responses (Claerebout and Vercruysse, 2000; Gasbarre et al., 2001; Muhle et al., 2001; Sigma Genosis, 2000). GenBank (http:// www.ncbi.nlm.nih.gov) was searched to identify cDNA or gene sequences that corresponded to an initial list of more than 900 candidate genes selected as potential array targets. These sequences were then used to perform BLASTn analysis against GenBank dbEST to identify bovine EST corresponding to cDNA clones originating from one of the five normalized cDNA libraries (Smith et al., 2001; Sonstegard et al., 2002). Twenty-two bovine genes of particular interest, not available in dbEST, were cloned by PCR amplification from cDNA samples using heterologous primers designed from alignments of sequences available on NCBI nr GenBank accessions (Zarlenga et al., 1995). From the initial list of genes, 473 bovine-specific reporters were successfully recovered and sequence validated.

All cDNA clones were arrayed into 96-well culture plates containing $1.2 \mathrm{ml}$ of $\mathrm{LB} / \mathrm{ampicillin}(50 \mu \mathrm{g} / \mathrm{ml})$ for growth of the master copy plates. Frozen stocks of the arrayed clones (BARC BOVCYTO1) were inoculated into 96deep-well culture plates containing $1.2 \mathrm{ml}$ of LB/ampicillin $(50 \mu \mathrm{g} / \mathrm{ml})$ for overnight growth at $37^{\circ} \mathrm{C}$ in a shaking incubator. PCR reactions were performed in $100 \mu$ l total volume containing $5 \mu \mathrm{l}$ bacterial culture. The PCR products were verified by $1 \%$ agarose gel electrophoresis and sequence validated (Sonstegard et al., 2002). Products that showed multiple bands or no yield were omitted. Reactions yielding appropriate products were manually transferred to storage plates. The PCR products were isopropanol-precipitated (Eisen and Brown, 1999), resuspended in $25 \mu$ l of $3 \times$ SSC (Standard Saline Citrate) and 
stored at $-20{ }^{\circ} \mathrm{C}$ until printing. The reporter sequences were printed onto GAPS II coated slides (Corning Inc., Corning, NY, USA) using an Affymetrix Arrayer 417 (Affymetrix, Inc., Santa Clara, CA, USA). The final array consisted of 576 reporters ( 473 genes, 26 positive controls, 77 negative controls) printed as 8 repetitions resulting in a microarray containing 4608 spots. The 473 gene reporters represented 381 unique transcripts. The 26 positive controls corresponded to glyceraldehyde 3-phosphate dehydrogenase (GAPDH) cDNA and the negative controls were comprised of $553 \times$ SSC and 22 PCR mix reactions. All reporters were spotted as eight replicates (two sets of four), such that, each set of four repetitions was located in a different block not in close proximity to its duplicate set of four. A complete listing of the reporter sequences can be found at www.anri.barc.usda.gov/idrl.

\subsection{Microarray hybridization and analysis}

Total RNA was extracted according to Chomczynski and Sacchi (1987). RNA concentrations were determined spectrophotometrically and their integrity checked by denaturating $0.8 \%$ agarose gel electrophoresis. Reactions were carried out in $30 \mu \mathrm{l}$ containing $50 \mu \mathrm{g}$ of total RNA and Cy3 or Cy5 dUTP (Amersham Biosciences, Piscataway, NJ, USA). The RNA was degraded using $15 \mu$ l of $0.1 \mathrm{~N} \mathrm{NaOH} /$ $2 \mathrm{mM}$ EDTA at $65^{\circ} \mathrm{C}$ for $30 \mathrm{~min}$. The samples were neutralized by addition of $15 \mu$ l of $0.1 \mathrm{~N} \mathrm{HCl}$. Cy3- and Cy5-labeled samples were synthesized for each animal and probes were combined for comparison using a loop design (Fig. 1) previously shown to have better properties than the reference design for small numbers of treatments (Kerr and Churchill, 2001). Design positions in the loop were randomly assigned only considering cyanine dye and use of a different animal from the opposite group. Then,

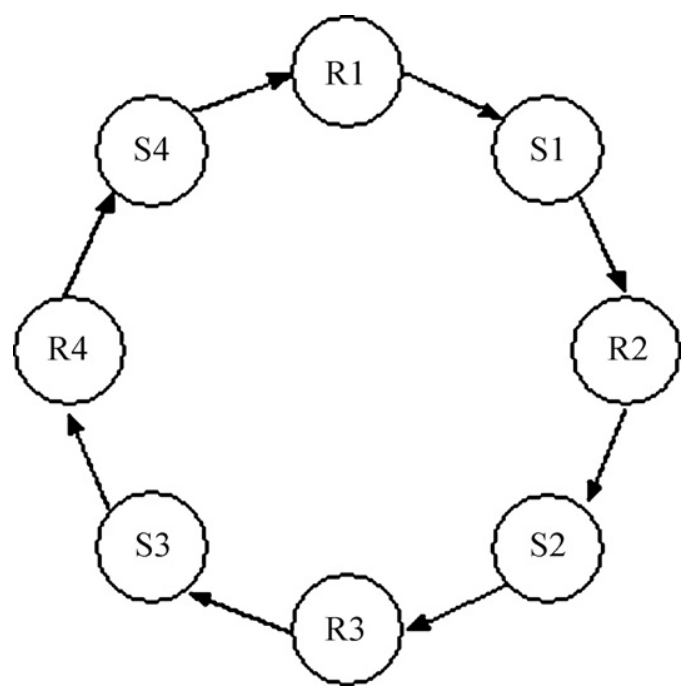

Fig. 1. Depiction of loop design used in hybridizing biological replicates representing parasite resistance $(\mathrm{R})$ and susceptible $(\mathrm{S})$ selection lines. Animals were randomly assigned to one of the four positions for each group. Arrow directions represent hybridization staining, with samples at the tail of the arrow stained with cyanine 3 and the sample at the head of the arrow stained with cyanine 5 . unincorporated fluorescent nucleotides were removed from the probe pool using Microcon YM-30 columns (Millipore, Billerica, MA, USA). Recovered probes were spiked with $5 \mu$ l of $4 \times$ hybridization blocking solution prior to desiccation by speed vac. The pellet was resuspended in $10 \mu$ l hybridization solution, $7 \mu$ l master $\operatorname{mix}$ and $3 \mu \mathrm{l} 20 \times$ SSPE. The mixture was denatured by heating at $95{ }^{\circ} \mathrm{C}$ for $3 \mathrm{~min}$ and loaded onto the microarray slides prehybridized for $1 \mathrm{~h}$ with $40 \mu \mathrm{l}$ of prehybridization solution. Hybridizations were carried out at $42{ }^{\circ} \mathrm{C}$ for $14-$ $18 \mathrm{~h}$. The slides were washed in $42{ }^{\circ} \mathrm{C}$ pre-warmed $2 \times \mathrm{SSC} /$ $0.1 \%$ SDS, $1 \times$ SSC $/ 0.1 \%$ SDS and room temperature $0.1 \times$ SSC for $10 \mathrm{~min}$ each and dried by centrifugation at $300 \mathrm{rpm}$ for $5 \mathrm{~min}$. Fluorescent intensities were captured using a Genepix 4000B scanner (Axon instruments, Inc., Union City, CA, USA), and acquired images were analyzed with the GenepixPro 4.0 software (Axon Instruments, Inc.). Spots were examined and those that exhibited poor quality (e.g., spot obscured by artifacts, dust or smearing) were eliminated from further analysis. To correct for overall differences between the Cy3 and Cy5 channels, a global normalization was used whereby a constant adjustment was used to force the distribution of the median ratios to have an average value of 1 . Preliminary data assessment was conducted using a number of SAS procedures (SAS Institute Inc., 2000). First, the ratio of the intensity measurements for the two dyes for each spot was plotted against the product of the measures, and a horizontal scatter was observed (data not shown). Therefore, no transformation was applied to the data. Conversion to a $\log _{2}$ scale was performed to make the data more normally distributed (Wolfinger et al., 2001).

The Mixed Procedure (SAS Institute Inc., 2000) was used to fit two mixed linear models based on the methods of Wolfinger et al. (2001) and Kerr et al. (2000). The first model is fit to account for systematic differences that are fit across all cDNA spots. Specifically,

$y_{i j k l m n o}=\mu+c_{i}+d_{j}+a_{k}+d a_{j k}+\varepsilon_{i j k l m n o}$,

where $y_{i j k l m n o}$ is the base 2 logarithm of the observed intensity for cDNA source $j$, treated with dye $i$, on array $k$, for selection group $l$, for block $m$, for row $n$, and replicate $o$. Here, $\mu$ represents the overall mean, $c_{i}$ is the fixed cDNA source effect, $d_{j}$ is the fixed dye effect, $a_{k}$ is the random array effect, $d a_{j k}$ is the random interaction of dye and array, and $\varepsilon_{i j k l m n o}$ is the random residual.

Next, if $r_{i j k l m n o}$ represents the realized residuals from the model (1), calculated by subtracting the fitted values for each effect in the model from the observed values, then the second level mixed linear model is fit independently for each cDNA source. Specifically, for cDNA $i$,

$$
\begin{aligned}
r_{i j k l m n o}= & \mu_{i}+d_{i j}+g_{i l}+a_{i k}+a b_{i k m}+a b r_{i k m n} \\
& +\gamma_{i j k l m n o},
\end{aligned}
$$

where $\mu_{i}$ is the overall mean, $d_{i j}$ is the fixed dye effect, $g_{i l}$ is the fixed selection line effect, $a_{i k}$ is the random array effect, $a b_{i k m}$ is the random block within array effect, $a b r_{i k m n}$ is the random row effect within array and block, and $\gamma_{i j k l m n o}$ is the random residual. Notice that all effects are fit independently for each cDNA. P-values were adjusted 
Table 1

Primer sequences and annealing temperatures used for amplification of each gene target evaluated by quantitative real-time RT-PCR.

\begin{tabular}{|c|c|c|c|c|}
\hline Gene & Amplicon length & Sense primer $\left(5^{\prime} \rightarrow 3^{\prime}\right)$ & Antisense primer $\left(5^{\prime} \rightarrow 3^{\prime}\right)$ & Annealing temperature $\left({ }^{\circ} \mathrm{C}\right)$ \\
\hline АСТВ & 149 & AGAAAGAGATCACTGCCCTG & ATCGTACTCCTGCTTGCTG & 57.2 \\
\hline CASP6 & 134 & CATATTGGACATGGTGAAGGG & AGCCAGAGATTGAGTAAACTTG & 57.2 \\
\hline $\mathrm{C} 3$ & 133 & AGTCCCTGGAGCTCATCAGAAA & AGTGCAAAGACCTTGACCACGTA & 57.2 \\
\hline CCL5 & 132 & ATGGCAGCAGTTGTCTTTATC & CGCAAGTTCAGGTTCAAGG & 57.2 \\
\hline CD163 & 104 & CTGTAATCTGCTCAGGAAATCG & GCAAGGAACACCATTCTCTTC & 57.2 \\
\hline CD1d & 102 & TACTACTGGTGTTCGTCCTTC & ATGGATGTGGTGAGAAGAGTC & 54.7 \\
\hline CD3E & 100 & CCTGTACCCAATCCAGACTATG & GAGATGGTGTCAGGAGTTGTC & 57.2 \\
\hline CD45 & 100 & TCCTCTGATGATGACAGCGACTT & CCTGAGCCGCAATCATCACT & 57.2 \\
\hline CD49d & 100 & GGCTCCATTGTGACTTGTG & AATCAGAAGGCATTCCATAGC & 57.2 \\
\hline $\mathrm{CDH} 13$ & 112 & CATGGCATAGAACTTGACCTTC & TACTAACCCACAGACCAAACC & 57.2 \\
\hline ESEL1 & 134 & TTGCCCAGGATTATAAAGTCAG & TCCAGACACATCAGAAGGTAG & 57.2 \\
\hline GA17 & 118 & TTATGAGGCACTTGTGGATTG & ACACCTGTGGGCATCAAC & 57.2 \\
\hline IGHG1 & 101 & ACAGTGGTGGAAGCACATAC & CACGCTGCTCACTGACAG & 54.7 \\
\hline IGJ & 108 & ACCATCTGTCTGACCTGTGCAA & AGGTCTCAGCGTCACTATCACAGAT & 57.2 \\
\hline IL6 & 106 & GGCTGCTCCTGGTGATGACT & CGCTTAATGAGAGCTTCGGTTT & 61.0 \\
\hline IL18 & 120 & TCAGATCACTTTGGCAAACTTG & ACAGTCAGAATCAGGCATATCC & 57.2 \\
\hline IRF1 & 140 & ACCGTGTGGCGTCAGTAG & CTTCCTCGTCCTCATCTGTTG & 57.2 \\
\hline MUC & 128 & ATGACAACTGGGACGTTCAAGAT & CACCACGTCATCCAAGGTGAT & 54.7 \\
\hline
\end{tabular}

using Bonferroni's method (Bonferroni, 1936), i.e., all $P$ values were divided by the number of cDNA to account for the multiple comparisons problem.

\subsection{Real-time RT-PCR validation}

To determine the accuracy of the array results, 18 genes were selected for validation by quantitative real-time RTPCR using individual isolates of MLN and SIM total RNA. Genes were chosen to cover different functional classes and different levels of significance as identified by the microarrays. The overall goal was to test more than $10 \%$ of differentially expressed genes for each group and each tissue type. Primer sequences for each gene were based on nucleotide sequences available in The Institute for Genomic Research (TIGR) Bos taurus Gene Index (http://www.tigr.org/tdb/tgi/btgi/; Table 1). Specificity of primers designed using Beacon Designer 2.12 Software (Premier Biosoft International, Palo Alto, CA, USA) was confirmed by sequencing of amplification products from bovine RNA using a CEQ8000XL automated sequencer (Beckman Coulter, Inc., Fullerton, CA, USA) and DTCS Quickstart chemistry (Beckman Coulter, Inc.). First-strand cDNA synthesis was performed in a $20 \mu \mathrm{l}$ volume using the iScript cDNA Synthesis Kit (Bio-Rad Laboratories, Hercules, CA, USA) and $495 \mathrm{ng}$ of total RNA according to the manufacturer's instructions. First-strand synthesis reactions were performed for each sample with (+RT) and without reverse transcriptase ( $-\mathrm{RT}$ ). Real-time PCR assays were performed in a total volume of $25 \mu \mathrm{l}$ using $2 \mu \mathrm{l}$ of first-strand cDNA as template, $1 \times$ iQ SYBR Green Supermix (Bio-Rad Laboratories) and $0.4 \mu \mathrm{M}$ of each gene-specific primer. Thermal cycling consisted of $3 \mathrm{~min}$ at $95{ }^{\circ} \mathrm{C}$ followed by 45 cycles of $94{ }^{\circ} \mathrm{C}$ for $15 \mathrm{~s}$, annealing temperature for $30 \mathrm{~s}$, and $72{ }^{\circ} \mathrm{C}$ for $30 \mathrm{~s}$. Primer sequences and annealing temperature used for amplification of each gene target are presented in Table 1. Experimental first-strand cDNA samples (+RT) were amplified in duplicate and a single negative control amplification (-RT) was performed for each sample. Amplification products were detected using an iCycler iQ Real-time Detection System (Bio-Rad Laboratories). For quantitation of transcript abundance, external standard calibration curves were generated in triplicate using $10^{2}-10^{8}$ molecules as template based on a single-stranded DNA molecule calculation. Standards were made from dilutions of PCR products containing the amplification region of interest for each gene. PCR products were purified by agarose gel electrophoresis and extracted using the QIAquick Gel Extraction Kit (Qiagen Inc., Valencia, CA, USA). Efficiency of amplification was calculated by the iCycler iQ Software Version 3.0A using the formula $E=10^{[-1 / \text { slope }]}-1$.

\section{Results}

\subsection{Parasitological data}

Analysis of fecal EPG values showed that the susceptible group yielded on average eight times more eggs in their feces over the course of the test period than the resistant group (Table 2 ). All susceptible animals were infected with $C$. oncophora, and the average worm burden was almost 250 times higher than the average of the resistant group. A single animal from the susceptible group contained Nematodirus helvetianus. No parasites of this genus were found in the resistant animals. Overall, EPG values of resistant animals did not differ significantly from susceptible animals $(P=0.125)$; however, EPG values were predictive of infection phenotype because worm counts were significantly different between groups $(P<0.005)$.

\subsection{Microarray overall gene expression patterns}

Based on previous validation efforts in our laboratory (data not shown), only genes that showed equal or greater

Table 2

Mean and standard deviation (S.D.) of the egg per gram (EPG) values and worm count of the resistant and susceptible groups.

\begin{tabular}{llll}
\hline Group & EPG $($ mean \pm S.D. $)$ & \multicolumn{2}{l}{ Genus $($ mean \pm S.D. $)$} \\
\cline { 2 - 4 } & & Cooperia & Nematodirus \\
\hline Susceptible & $85 \pm 117.8$ & $3213 \pm 634$ & $63 \pm 125$ \\
Resistant & $10 \pm 4.2$ & $13 \pm 25$ & $0 \pm 0$ \\
\hline
\end{tabular}


Table 3

Genes more highly expressed in the mesenteric lymph node (MLN) of resistant animals.

\begin{tabular}{|c|c|c|}
\hline Gene name & Gene symbol & FI \\
\hline \multicolumn{3}{|l|}{ Immunoglobulins } \\
\hline Immunoglobulin J chain & IGJ & 1.53 \\
\hline Ig kappa-4 light chain variab & IGKV@ & 1.61 \\
\hline \multicolumn{3}{|l|}{ Antigen presentation } \\
\hline WC1.1 & M130 & 1.39 \\
\hline CD45 & PTPRC & 1.43 \\
\hline MHC class III histocomp Ag & HLA-B & 1.34 \\
\hline \multicolumn{3}{|l|}{ Cell activation and motility } \\
\hline CD1d & CD1D & 1.42 \\
\hline CD6 & CD6 & 1.69 \\
\hline CD86 & CD86 & 1.51 \\
\hline $\mathrm{CD} 22$ & $\mathrm{CD} 22$ & 1.58 \\
\hline B cell activating factor & TNFSF13B & 1.69 \\
\hline Extracellular matrix protein & ECM2 & 1.71 \\
\hline CD153 & TNFSF8 & 1.53 \\
\hline CD163 & CD163 & 2.14 \\
\hline Endothelial monocyte-activat prot & SCYE1 & 1.41 \\
\hline Protein inhibitor of nNOS & PIN & 1.25 \\
\hline \multicolumn{3}{|l|}{ Tissue factors } \\
\hline Mucin & DMBT1 & 2.17 \\
\hline IGF binding protein 3 & IGFBP3 & 1.40 \\
\hline IGF binding protein 4 & IGFBP4 & 1.40 \\
\hline IGF-II & IGF2 & 1.55 \\
\hline IGF R type & IGF2R & 1.96 \\
\hline Memb-type matrix metalloprot 1 & MMP14 & 1.71 \\
\hline Bone morphogenetic protein 4 & BMP4 & 1.67 \\
\hline Bone morphogenetic protein R II & BMPR2 & 1.61 \\
\hline Ephrin type-B R 3 & ЕРHB3 & 1.39 \\
\hline Semaphorin 4B & SEMA4B & 1.34 \\
\hline Endothelin converting enzyme 1 & ECE1 & 1.55 \\
\hline Epidermal growth factor R subst & EPS15 & 1.57 \\
\hline Prolactin receptor & PRLR & 2.53 \\
\hline Follistatin precursor (FS) & FST & 1.21 \\
\hline Annexin III & ANXA3 & 1.22 \\
\hline Caspase-6 precursor & CASP6 & 1.28 \\
\hline \multicolumn{3}{|l|}{ Cytokines and chemokines } \\
\hline IL-18 & IL18 & 1.51 \\
\hline IFN alpha/beta receptor-2 & IFNAR1 & 1.52 \\
\hline IFN gamma receptor 1 & IFNGR1 & 1.61 \\
\hline IFN regulatory factor 6 & IRF6 & 2.01 \\
\hline IFN-related developmental regulat & IFRD2 & 1.28 \\
\hline T-cell-specific T-box transc fact & TBX21 & 1.27 \\
\hline TNF intracell domain-interact prot & CKIP-1 & 1.21 \\
\hline CD154 & TNFSF5 & 1.42 \\
\hline TNF $\beta$ R 1 & TNFRSF1A & 1.67 \\
\hline CD27 & TNFRSF7 & 1.50 \\
\hline Oncostatin $\mathrm{M}$ receptor $\mathrm{b}$ & OSMR & 1.51 \\
\hline Small Inducible Cytokine A21 Prec & CCL21 & 1.69 \\
\hline CD127 & IL7R & 1.41 \\
\hline IK cytokine & IK & 1.21 \\
\hline CCR5 & CCR5 & 1.30 \\
\hline CCR9 & CCR9 & 1.95 \\
\hline \multicolumn{3}{|l|}{ Cell communication and cycle } \\
\hline Activating transcription factor 4 & ATF4 & 1.82 \\
\hline Lysosomal trafficking regulator & CHS1 & 1.41 \\
\hline Nucleosome assembly protein; NAP & NAP1L1 & 1.21 \\
\hline t-complex protein 1 beta subunit & $\mathrm{CCT} 2$ & 1.38 \\
\hline \multicolumn{3}{|l|}{ Complement } \\
\hline Complement component $1 \mathrm{r}$ subcomp & C1R & 1.53 \\
\hline Complement C4 precursor & $\mathrm{C} 4 \mathrm{~A}$ & 1.91 \\
\hline \multicolumn{3}{|l|}{ Adhesion molecules } \\
\hline Vascular cadherin-2 & PCDH12 & 1.92 \\
\hline E-selectin ligand-1 & GLG1 & 1.75 \\
\hline CD162; P-selectin glycop ligand-1 & SELPLG & 1.40 \\
\hline CD11c & ITGAX & 1.24 \\
\hline
\end{tabular}

Table 3 (Continued)

\begin{tabular}{lll}
\hline Gene name & Gene symbol & FI \\
\hline CD47/IAP protein & CD47 & 1.35 \\
CD49d & ITGA4 & 1.33 \\
CD103; Integrin alpha E2 & ITGAE & 1.41 \\
Unknown function & & \\
I-kappa-B-interacting Ras-like prot 2 & KBRAS2 & 1.38 \\
\hline
\end{tabular}

$\mathrm{FI}=$ fold increase.

than 1.2-fold difference between the resistant and susceptible groups were considered for further analysis. Hybridization results from the microarrays showed that in MLN and SIM tissues, 109 and 42 reporters were differentially expressed $(P<0.05)$ between the resistant and susceptible groups, respectively. Compensating for partial duplication of some genes within the array, significant changes in expression were observed in 100 unique genes in the MLN (61 more highly expressed in the resistant group and 39 more highly expressed in the susceptible group) and 38 for the SIM (18 more highly expressed in the resistant group and 20 more highly expressed in the susceptible group). For purposes of annotation, the differentially expressed genes were organized into 10 functional classes based on BLASTn sequence alignment of the reporters to the human RefSeq database. Annotations of these genes included correspondence to immunoglobulins, antigen presentation, cell activation and motility, cytokines, chemokines, cell communication and cell cycle, tissue factors, complement, adhesion molecules and genes with unknown functions (Tables 3-6).

\subsection{Gene expression patterns corresponding to phenotype}

\subsubsection{Resistant animals}

In the SIM, the transcript of IgE receptor gene FCER1A was present at significantly $(P<0.05)$ higher levels of expression in resistant animals. The expression of IGJ (Ig J chain), an important component for the secretion of Ig, was found at higher levels in the MLN of resistant animals. A subset of cytokine genes related to TNF was also related to resistance, where four genes (CKIP-1, TNFSF5, TNFRSF1A and TNFRSF7) were highly expressed in the MLN of the resistant group. Of the adhesion molecules, genes encoding integrins were most related to resistance, where four genes (ITGAX, CD47, ITGA4 and ITGAE) had higher levels of expression in the MLN of resistant animals.

Among the genes encoding tissue factors, the greatest differences were observed in the SIM where transcripts coding for mucin (DMBT1), pepsinogen (PGA@), fibroblast grow factors (FGFR2) and tubulin (TUBA2) were upregulated in resistant animals. Although eight genes were observed at higher levels in the MLN of the susceptible group, 14 genes related to tissue factors were identified with higher expression in the MLN of resistant animals. Genes related to complement, like $\mathrm{C} 1 \mathrm{R}$ and $\mathrm{C} 4 \mathrm{~A}$, also appeared in higher levels, while the complement component 3 (C3) showed higher expression in the susceptible SIM. Genes related to monocytes/macrophages also appeared highly expressed in resistant tissues, as observed 
Table 4

Genes more highly expressed in the mesenteric lymph node (MLN) of susceptible animals.

\begin{tabular}{|c|c|c|}
\hline Gene name & Gene symbol & FI \\
\hline \multicolumn{3}{|l|}{ Immunoglobulins } \\
\hline Fc R gamma chain & FCER1G & 1.21 \\
\hline IgG Fc binding protein & FCGBP & 1.26 \\
\hline \multicolumn{3}{|l|}{ Antigen presentation } \\
\hline $\mathrm{CD} 3 \delta$ & CD3D & 1.23 \\
\hline CD74 & CD74 & 1.25 \\
\hline MHC class I heavy chain & $\mathrm{MHCI}$ & 1.24 \\
\hline \multicolumn{3}{|l|}{ Cell activation and motility } \\
\hline Actin $\beta$ & ACTB & 1.37 \\
\hline Lymphocyte-specific protein 1 & LSP1 & 1.32 \\
\hline CD96 & TACTILE & 1.37 \\
\hline CD110 & MPL & 1.43 \\
\hline Toll-like R 4 & TLR4 & 1.27 \\
\hline CD59 & CD59 & 1.32 \\
\hline \multicolumn{3}{|l|}{ Tissue factors } \\
\hline IGF binding protein 6 & IGFBP6 & 1.41 \\
\hline FGF-binding protein & HBP17 & 1.41 \\
\hline Matrix metalloproteinase RASI-1 & MMP19 & 1.30 \\
\hline MMP 2 & MMP2 & 1.26 \\
\hline MMP23A & MMP23A & 1.24 \\
\hline Tissue inhibitor of metalloprot 1 & TIMP1 & 1.33 \\
\hline Neuromodulin & GAP43 & 1.25 \\
\hline Cartilage matrix protein & MATN1 & 1.20 \\
\hline \multicolumn{3}{|l|}{ Cytokines and chemokines } \\
\hline IFN-induced 35 kDa protein & IFI35 & 1.40 \\
\hline IFN regulatory factor 1 & IRF1 & 1.28 \\
\hline IL-2 R $\gamma$ & IL2RG & 1.22 \\
\hline IL-6 & IL6 & 1.34 \\
\hline TGF $\beta$ & TGFB1 & 1.21 \\
\hline IL-16 & IL16 & 1.34 \\
\hline CCR8 & CCR8 & 1.32 \\
\hline CXCR3 & CXCR3 & 1.24 \\
\hline CXCL16 & CXCL16 & 1.22 \\
\hline G protein coupled R BONZO & CXCR6 & 1.25 \\
\hline GMCSF & CSF2 & 1.23 \\
\hline RANTES & CCL5 & 1.40 \\
\hline \multicolumn{3}{|l|}{ Adhesion molecules } \\
\hline Cadherin 13 & $\mathrm{CDH} 13$ & 1.33 \\
\hline Protocadherin 7 & PCDH7 & 1.45 \\
\hline LECAM-1 & SELL & 1.28 \\
\hline CD164 & CD164 & 1.28 \\
\hline \multicolumn{3}{|l|}{ Unknown function } \\
\hline B-cell CLL/lymphoma 7B & BCL7B & 1.27 \\
\hline B-cell CLL/lymphoma 9 & BCL9 & 1.58 \\
\hline GPR21 & GPR21 & 1.38 \\
\hline
\end{tabular}

$\mathrm{FI}=$ fold increase.

for three genes from the cell activation class (CD163, SCYE1 and PIN).

\subsubsection{Susceptible animals}

From the immunoglobulin-associated class, a subclass of genes encoding Ig chains was observed at significantly $(P<0.05)$ higher levels in the SIM from the susceptible group the only exception being IGKV@, which showed higher levels in the resistant MLN. Among this subclass of Ig chain transcripts, genes encoding different isotypes were found, including IgA, IgG and IgM. The ones encoding $\operatorname{IgG}$ and IgM chains were the ones that presented the highest differential expression between the resistant and susceptible groups, with levels of expression in the
Table 5

Genes more highly expressed in the small intestine mucosa (SIM) of resistant animals.

\begin{tabular}{lll}
\hline Gene name & Gene symbol & FI \\
\hline $\begin{array}{l}\text { Immunoglobulins } \\
\text { IgE high affinity R alpha subunit }\end{array}$ & FCER1A & \\
Cell activity and motility & & 1.57 \\
CD79a & IGBP1 & \\
CD63 & CD63 & 1.20 \\
Protein inhibitor of nNOS & PIN & 1.20 \\
Tissue factors & & 1.25 \\
Mucin & DMBT1 \\
Pepsinogen A precursor & PGA@ & \\
FGF R 2 & FGFR2 & 1.55 \\
Growth hormone & GH1 & 1.39 \\
Cartilage matrix protein & MATN1 & 1.22 \\
Tubulin alpha-2 subunit & TUBA2 & 1.22 \\
Follistatin precursor (FS) & FST & 1.10 \\
& & 1.22 \\
Cytokines and chemokines & & 1.24 \\
IFN-induced protein 1-8U & IFITM3 \\
IL-3 promoter transcription & NFIL3 & \\
Pre-B-cell colony-enhancing factor & PBEF & 1.50 \\
Hemofiltrate CC chemokine 1 & CCL14 & 1.20 \\
Cell communication and cycle & & 1.21 \\
Cyclin C & CCNC \\
Placental protein 15 & NUTF2 & 1.20 \\
t-complex protein 1 beta subunit & CCT2 & \\
\hline
\end{tabular}

$\mathrm{FI}=$ fold increase

susceptible group 2-fold higher than half of the genes. Another subset of genes upregulated in both the MLN and the SIM susceptible animals included TCRs, represented by two genes (CD3D and CD3E). The genes encoding the cytokine IL2 receptor gamma (IL2RG) and IL4 receptor alpha chain (IL4R) showed higher expression in both susceptible tissues, as did two IFN modulator genes (IFI35 and IRF1). Conversely, a number of other IFN modulator genes also showed higher levels within both tissues of the resistant group.

\subsection{Validation of microarray results using real-time $R T-P C R$}

Table 7 summarizes the real-time RT-PCR expression data for each of the 18 gene targets used for validation. Amplification efficiencies ranged from $84.1 \%$ to $103.0 \%$ and the correlation coefficient for all standard calibration curves was $\geq 0.995$. The coefficient of variation based on the cycle threshold ranged from $0.5 \%$ to $4.9 \%$ and averaged $1.5 \%$ ( $n=18$ assays; Table 7$)$.

For MLN microarray results, 10 of the 14 gene expression profiles detected by the microarray were confirmed. Similarly, results for 6 (75\%) of the 8 genes from the SIM comparisons were confirmed. Overall, for 22 genes deemed significantly different by microarray $(P<0.05), 17$ genes $(77 \%)$ were confirmed, 9 of which showed significant $(P \leq 0.10)$ differences in expression between the resistant and susceptible groups.

\section{Discussion}

Global analysis by DNA microarray hybridization can identify and differentiate gene transcript expression in different cells and tissues (Dietz et al., 2000). The present 
Table 6

Genes more highly expressed in the small intestine mucosa (SIM) of susceptible animals.

\begin{tabular}{|c|c|c|}
\hline Gene name & Gene symbol & FI \\
\hline \multicolumn{3}{|l|}{ Immunoglobulins } \\
\hline Ig lambda light chain variab & IGLV@ & 1.45 \\
\hline IgA heavy chain constant region & IGHAI & 1.40 \\
\hline IgG1 heavy chain constant region & IGHG1 & 2.14 \\
\hline IgG2a/IgG3 heavy chain const reg & IGHG2 & 2.11 \\
\hline $\operatorname{IgM}$ & IGM & 2.25 \\
\hline IgM heavy chain variable region & IGHV@ & 2.30 \\
\hline IgM heavy chain constant region & IGHM & 1.52 \\
\hline Ig heavy chain variable region & IGHV@ & 1.64 \\
\hline \multicolumn{3}{|l|}{ Cell activation and motility } \\
\hline Actin $\beta$ & ACTB & 1.30 \\
\hline CD81 & CD81 & 1.31 \\
\hline CD151 & CD151 & 1.28 \\
\hline CD68 & CD68 & 1.22 \\
\hline \multicolumn{3}{|l|}{ Cytokines and chemokines } \\
\hline IFN regulatory factor 1 & IRF1 & 1.31 \\
\hline IL-1 receptor antagonist & IL1RN & 1.29 \\
\hline IL-4 $\mathrm{R} \alpha$ chain & IL4R & 1.21 \\
\hline MCP2 & CCL8 & 1.67 \\
\hline RANTES & CCL5 & 1.44 \\
\hline \multicolumn{3}{|l|}{ Complement } \\
\hline Complement component 3 & C3 & 1.33 \\
\hline \multicolumn{3}{|l|}{ Adhesion molecules } \\
\hline Ly-9 & LY9 & 1.45 \\
\hline \multicolumn{3}{|l|}{ Antigen presentation } \\
\hline TCR CD $3 \varepsilon$ chain & CD3E & 1.27 \\
\hline
\end{tabular}

$\mathrm{FI}=$ fold increase

study applies microarray analyses to problems related to the health of livestock. We report the construction of a microarray containing 473 reporter sequences representing 381 distinct immune related genes, and the use of this array to study gene expression patterns in the bovine tissues involved in affecting levels of resistance and/or susceptibility to GI nematodes.

Previous studies have documented that GI nematodes of bovine evoke a number of host immune responses that enhanced the level of immunity, including a delay in parasite development time and a reduction in the number of eggs produced by female worms (Michel, 1967; Michel et al., 1972). These manifestations vary with worm species, parasite exposure to the host, and host factors such as age, sex, hormonal and nutritional status, and genetic make-up (Vercruysse and Claerebout, 1997). The animals in the present study were similar in age, maintained under the same management, and grazed on the same pastures until necropsy. Therefore, it is evident that the resistant group presented a very strong protective immune response against the intestinal worm Cooperia compared to the susceptible group, as confirmed by parasite burdens. At the same time, the differences seen in fecal egg counts were not as great, indicating smaller differences in worm numbers for parasites in the abomasum (i.e. Ostertagia) (data not shown). The use of the microarray in studies of gene expression patterns in this host-parasite system is in progress.

The microarray identified genes with elevated expression levels in the MLN and SIM of genetically resistant or susceptible animals. Our findings were partially confirmed by real-time RT-PCR. Although variability in the microarray and real-time RT-PCR results has been observed (Callow et al., 2000), in our hands, the two techniques agreed in $77.2 \%$ of the genes evaluated. The lack of statistical significance for some genes when analyzed by the real-time RT-PCR could be due to the low number of samples (four animals) tested, while the methodology and the replicates used for the microarray permitted a more robust statistical analysis of the data. When analyzing micrarrays, a second problem is assimilating relative changes in gene expression with biological significance.

Table 7

Gene expression ratios of the resistant over the susceptible (ratio R/S) groups for 18 genes as detected by the real-time RT-PCR compared to the results determined by the microarray analysis.

\begin{tabular}{|c|c|c|c|c|c|c|c|c|c|}
\hline \multicolumn{2}{|l|}{ Genes } & \multicolumn{4}{|l|}{ MLN } & \multicolumn{4}{|l|}{ SIM } \\
\hline \multirow[t]{2}{*}{ Name } & \multirow[t]{2}{*}{ Symbol } & \multicolumn{2}{|c|}{ Microarray } & \multicolumn{2}{|c|}{ Real-time RT-PCR } & \multicolumn{2}{|c|}{ Microarray } & \multicolumn{2}{|c|}{ Real-time RT-PCR } \\
\hline & & Ratio R/S & neglogP & Ratio R/S & $P$-value & Ratio R/S & neglogP & Ratio R/S & $P$-value \\
\hline Ig J Chain & IGJ & 1.53 & 9.72 & 2.15 & 0.23 & - & - & - & - \\
\hline IgG heavy chain const reg & IGHG1 & - & - & - & - & -2.25 & 27.62 & -4.73 & 0.10 \\
\hline CD45 & PTPRC & 1.43 & 12.04 & 1.60 & 0.03 & - & - & - & - \\
\hline Dendritic cell protein & GA17 & - & - & - & - & 1.21 & 0.41 & -1.10 & 0.77 \\
\hline T-cell receptor CD3 $\varepsilon$ & CD3E & - & - & - & - & -1.39 & 11.10 & -5.45 & 0.01 \\
\hline Actin- $\beta$ & АCTB & -1.38 & 28.39 & 1.00 & 1.00 & -1.38 & 2.12 & -3.62 & 0.01 \\
\hline CD1D & CD1D & 1.52 & 6.92 & 1.47 & 0.08 & - & - & - & - \\
\hline CD163 & CD163 & 2.14 & 13.96 & 2.64 & 0.21 & - & - & - & - \\
\hline IL-6 & IL6 & -1.33 & 4.38 & -2.20 & 0.46 & - & - & - & - \\
\hline IL-18 & IL18 & 1.37 & 11.12 & 1.39 & 0.20 & - & - & - & - \\
\hline Interferon regulatory fact 1 & IRF1 & -1.27 & 2.08 & -1.32 & 0.17 & -1.31 & 4.74 & -4.76 & 0.01 \\
\hline RANTES & CCL5 & -1.41 & 5.50 & -1.02 & 0.95 & -1.44 & 9.53 & -3.03 & 0.01 \\
\hline Caspase- 6 precursor & CASP6 & 1.29 & 1.06 & 1.51 & 0.18 & - & - & - & - \\
\hline Mucin & DMBT1 & 2.19 & 4.67 & 2.23 & 0.13 & 1.59 & 1.33 & -1.24 & 0.68 \\
\hline Complement component 3 & $\mathrm{C} 3$ & - & - & - & - & -1.33 & 7.88 & -3.34 & 0.04 \\
\hline Cadherin 13 & CDH13 & -1.33 & 1.74 & 1.00 & 0.87 & - & - & - & - \\
\hline CD49d & ITGA4 & 1.33 & 2.54 & 1.35 & 0.09 & - & - & - & - \\
\hline E-selectin ligand & GLG1 & 1.67 & 5.44 & -1.11 & 0.42 & - & - & - & - \\
\hline
\end{tabular}

MLN = mesenteric lymph node; SIM = small intestine mucosa. 
Early studies of differential gene expression defined 2- or 3-fold differences as target levels for biological significance; however, other studies have indicated that such dramatic variations may not be required to invoke meaningful changes in the host response (Chen et al., 1997; Newton et al., 2001; Pan et al., 2002) and the increased replication allows detection of small changes of a particular gene at thresholds of statistical significance (Gibson, 2002). Keane et al. (2006) also considered fold differences as low as 1.1 when they identified changes in gene expression in sheep genetically resistant to GI nematodes. Thus, selecting cut-off values for a causal relationship between gene expression and biological significance values can be problematic; however, in this study, genes showing statistically significant $(P<0.05)$ variation and $\geq 1$.2-fold difference in expression levels between the two experimental groups, as detected by mixed model analysis of variance (SAS Institute Inc., 2000), were reported.

For overall analysis, we focused on the expression of the genes verified by the real-time RT-PCR, but also included in the discussion related genes that showed differential expression between groups as identified by the microarray that could participate in the same pathway and could be co-stimulated or co-inhibited. Expression patterns in SIM and MLN revealed that genes related to IgE receptors, TNF cytokines, integrins, complement, monocytes/macrophages and some tissue factors (DMBT1, PGA@, FGFR2 and TUBA2) were expressed at higher levels in resistant animals, while genes related to Ig chains and TCRs were highly expressed in susceptible animals.

The patterns observed for genes related to Igs in the SIM were very distinct between the resistant and susceptible groups. Higher levels of Ig chain transcripts, including IgG, IgA and IgM classes, were observed in susceptible animals, and higher levels of transcripts for $\operatorname{IgE}$ receptors and $\mathrm{Ig} \mathrm{J}$ chain in the resistant animals. The higher levels of antibodies in susceptible SIM corroborate with the higher levels of IL6 in susceptible tissues, which could increase the production of antibodies by stimulating B cells (Curfs et al., 1997). However, these results contrast with previous works in Romney sheep that found increased levels of circulating antibodies related to resistance against Trichostrongylus colubriformis (Pernthaner et al., 1996). The observation regarding Ig-associated genes should be analyzed very carefully, as they may be a result of a lower level of stimulation of the immune system due to the lack of parasites at the SIM of resistant calves. However, if this last hypothesis is correct, it is interesting to verify that high parasite burdens in susceptible animals stimulate higher expression of Ig chains, and not IgE receptors.

Complement component C3 is a major opsonic protein of the complement system and plays a central role for both classical and alternative complement activation pathways (Nielsen and Leslie, 2002). Although C3 expression was confirmed by RT-PCR at higher levels in the susceptible SIM, other complement genes were found by the microarray at higher levels in resistant MLN. These results complicate the role of complement in fighting nematode infections. However, previous studies with hepatocyte cells have observed that IL6, alone or in combination with other cytokines such as IL1 $\beta$ and IFN $\gamma$, is able to enhance the expression of C3 mRNA in cell cultures (Andrews et al., 2003).

Of the adhesion molecule genes, the integrins were found most associated with resistance against GI nematodes. Microarray analysis detected four genes showing higher levels of expression in both resistant MLN and SIM and among them, the expression of ITGA4 was confirmed by real-time RT-PCR. Integrins are important adhesion molecules responsible for cell interactions that regulate proliferation, differentiation, migration and recruitment into tissues and in intestinal immunity. Also, they are important regulators of mast cells and eosinophils which are involved in nematode immunity (Stevenson et al., 2001). Although little is known about the relationship between expression levels of integrins and resistance to nematodes, Gurish et al. (2004) observed that the traffic of mast cells to the intestine requires the expression of the integrin a4B7, and Stevenson et al. (2001) verified that after $T$. colubriformis infection in sheep, a number of integrins, including CD11a, Cd11b, CD11c, CD44 and CD49d, are expressed in neutrophils and eosinophils.

Among the genes from the antigen presentation class, CD45 was observed at a higher level in the resistant MLN, while CD3E was higher in the susceptible SIM. These results agree with observations of Pernthaner et al. (1996) who studied resistant Romney line-bred sheep. These authors found higher levels of CD45R and lower levels of CD5, CD4 and T19 in the resistant sheep, relative to a susceptible, high EPG group of animals. In addition to $\mathrm{CD} 3 \mathrm{E}$, microarrays also showed the $\mathrm{CD} 3 \delta$ chain to be more highly expressed in tissues of susceptible animals. Gasbarre et al. (2001) observed an absolute and relative increase in the CD3 cells both in the lymph node and at the site of the infection; however, the difference between resistant and susceptible animals was not studied. These data suggest that both animals may have an increase in CD3 cells, though the increase is greater in susceptible animals.

In general, genes related to tissue factors were highly expressed in resistant tissues. At the SIM, four genes (DMBT1, PGA@, FGFR2 and TUBA2) were associated with parasite resistance. At this time, it is difficult to know whether these genes are involved in the protection of the mucosa, the recovery of intestinal damage, or an increase in motility of the intestine wall; however, changes in these gene expression patterns are consistent with both tissue pathways and immunological pathways being involved in the differential response of resistant animals.

Some pro-inflammatory cytokines were elevated in the resistant MLN and SIM in the present study, among them TNF and IFN modulators, indicating the importance of the draining lymph node and also local response in stimulating the response against GI nematodes. Using the same Angus population, Li et al. (2007) also identified in the small intestine upregulation in pro-inflammatory cytokines such as MIP- $1 \alpha$, IL-10 and IL-6, but some of these genes were not seen differently between resistant and susceptible in the present work while IL-6 was identified as upregulated in susceptible SIM. 
Divergences in gene expression were also observed when the results were compared to gene expression of other ruminants. Sheep infected with $T$. colubriformis presented resistance associated to Toll-like receptors and free radical producing genes (Ingham et al., 2008) and infected with multiple nematodes (Trichostrongylus and Cooperia) had upregulation of genes involved with acquired immune responses as immunoglobulins and MHCII (Diez-Tascón et al., 2005). Except for the immunoglobulins, these genes were either not tested or with similar expression between groups in the present study. On the other hand, some genes had similar results. The gene IFI35, identified in the present work as more highly expressed in the susceptible MLN, was also as upregulated in the duodenum of susceptible sheep. Thus, genes related to IFN, MHC, and tissue factors along with those related to integrins and annexins, should have their roles better elucidated in future experiments provided their changes in expression levels can be confirmed in more than one study (Diez-Tascón et al., 2005; Keane et al., 2006). IgE receptor is also a possible important gene, once it was upregulated in the SIM of resistant calves and in sheep resistant for Haemonchus (Ingham et al., 2008).

These divergences highlight the complexity of the responses to GI nematodes and could reflect the great variations among individuals as seen by Li et al. (2007) and other works (Almeria et al., 1997, 1998). They may also be related to the limitations and differences among the methodologies used in each work to measure gene expression.

The gene expression patterns observed in susceptible and resistant animals do not align with either the TH1- or TH2-type immune paradigms. This is corroborated by higher levels of expression in susceptible animals of both TH1 and TH2 genes, such as IL6 and immunoglobulin chains (which could be more related to a $\mathrm{TH} 2$ response), IRF1 (more related to a TH1 response) and RANTES (which can co-stimulate TH1- and TH2-type cytokines such as IFN $\gamma$, IL-2 and IL-5) (Lillard et al., 2001). These results support the idea that an effective immune response against GI nematodes is not restricted to $\mathrm{TH} 1$ - or $\mathrm{TH} 2$-types (Almeria et al., 1997) and contrast with studies in rodent models indicating that $\mathrm{TH} 2$ responses are involved in resistance to intestinal dwelling nematodes (Urban et al., 1992).

Our results demonstrate that the microarray is a valuable tool for identifying candidate genes contributing to susceptibility or resistance to infection by GI nematodes in cattle. The magnitude of the differences between resistant and susceptible groups suggests that the pathways for generating effective immune responses against GI nematodes could involve small but replicable differences in expression patterns of multiple genes or groups of genes. The results also show the potential for multiple resistance mechanisms in the immune response and that these mechanisms may be parasite specific, site specific and burden dependent. A better definition of these factors will depend upon the study of sufficient numbers of resistant and susceptible calves. The identification of genes involved in this process could help the mapping of quantitative trait loci. Furthermore, the data provided herein may facilitate identification of causative genetic variation affecting immunity of cattle to parasites of the GI tract (Sonstegard and Gasbarre, 2001), and identification of possible novel mechanisms of parasite resistance ( $\mathrm{Li}$ et al., 2007).

\section{Acknowledgements}

This study was supported by EMBRAPA/LABEX, CNPqBrazil (Conselho Nacional de Pesquisa) and CAPES-Brazil (Coordenação de Aperfeiçoamento de Pessoal de Nível superior).

\section{References}

Almeria, S., Canals, A., Zarlenga, D.S., Gasbarre, L.C., 1997. Quantification of cytokine gene expression in lamina propria lymphocytes of cattle following infection with Ostertagia ostertagi. J. Parasitol. 83, 10511055.

Almeria, S., Canals, A., Gomez-Munoz, M.T., Zarlenga, D.Z., Gasbarre, L.C., 1998. Characterization of protective immune responses in local lymphoid tissues after drug-attenuated infections with Ostertagia ostertagi in calves. Vet. Parasitol. 80, 53-64.

Andrews, E., Feldhoff, P., Feldhoff, R., Lassiter, H., 2003. Comparative effects of cytokines and cytokine combinations on complement component 3 secretion by HepG2 cells. Cytokine 23, 164-169.

Balic, A., Bowles, V.M., Meeusen, E.N.T., 2000. The immunobiology of gastrointestinal nematode infections in ruminants. Adv. Parasitol. 45, $181-241$.

Bonferroni, C.E., 1936. Teoria statistica delle classi e calcolo delle probabilit à. Pubblicazioni del R Istituto Superiore di Scienze Economiche e Commerciali di Firenze 8, 3-62.

Callow, M.J., Dudoit, S., Gong, E.L., Speed, T.P., Rubin, E.M., 2000. Microarray expression profiling identifies genes with altered expression in HDL-deficient mice. Genome Res. 10, 2022-2029.

Chen, Y., Dougherty, E.R., Bittner, M.L., 1997. Ratio-based decisions and the quantitative analysis of cDNA microarray images. J. Biomed. Opt. 2, 364-367.

Chomczynski, P., Sacchi, N., 1987. Single-step method of RNA isolation by acid guanidinium thiocyanate-phenol-chloroform extraction. Anal. Biochem. 162, 156-159.

Claerebout, E., Vercruysse, J., 2000. The immune response and the evaluation of acquired immunity against gastrointestinal nematodes in cattle: a review. Parasitology 120, s25-s42.

Curfs, J.H., Meis, J.F., Hoogkamp-Korstanje, J.A., 1997. A primer on cytokines: sources, receptors, effects, and inducers. Clin. Microbiol. Rev. 10, 742-780.

Dietz, A.B., Bulur, P.A., Knutson, G.J., Matasic, R., Vuk-Pavlovic, S., 2000. Maturation of human monocyte-derived dendritic cells studied by microarray hybridization. Biochem. Biophys. Res. Commun. 275, 731738.

Diez-Tascón, C., Keane, O.M., Wilson, T., Zadissa, A., Hyndman, D.l., Baird, D.B., McEwan, J.C., Crawford, A.M., 2005. Microarray analysis of selection lines from outbred populations to identify genes involved with nematode parasite resistance in sheep. Physiol. Genomics 21, 59-69.

Eisen, M.B., Brown, P.O., 1999. DNA arrays for analysis of gene expression. Methods Enzymol. 303, 179-205.

Gasbarre, L.C., Leighton, E.A., Davies, C.J., 1990. Genetic control of immunity to gastrointestinal nematodes of cattle. Vet. Parasitol. 37, 257272.

Gasbarre, L.C., 1997. Effects of gastrointestinal nematode infection on the ruminant immune system. Vet. Parasitol. 72, 327-343.

Gasbarre, L.C., Leighton, E.A., Sonstegard, T., 2001. Role of the bovine immune system and genome in resistance to gastrointestinal nematodes. Vet. Parasitol. 98, 51-64.

Genchi, C., Madonna, M., Traldi, G., 1989. Epidemiology of Ostertagia ostertagi in dairy cow from different breeding systems. Parasitologia 31, 123-132.

Gibson, G., 2002. Microarrays in ecology and evolution: a preview. Mol. Ecol. 11, 17-24.

Gurish, M.F., Bryce, P.J., Tao, H., Kisselgof, A.B., Thornton, E.M., Miller, H.R., Friend, D.S., Oettgen, H.C., 2004. IgE enhances parasite clearance and regulates mast cell responses in mice infected with Trichinella spiralis. J. Immunol. 172, 1139-1145. 
Herlich, H., 1976. Attempts to produce protection against Ostertagia ostertagi in cattle. Am. J. Vet. Res. 37, 61-64.

Ingham, A., Reverter, A., Windon, R., Hunt, P., Menzies, M., 2008. Gastrointestinal nematode challenge induces some conserved gene expression changes in the gut mucosa of genetically resistant sheep. Int. J. Parasitol. 38, 431-442.

Keane, O.M., Zadissa, A., Wilson, T., Hyndman, D.L., Greer, G.J., Baird, D.B., McCulloch, A.F., Crawford, A.M., McEwan, J.C., 2006. Gene expression profiling of naïve sheep genetically resistant and susceptible to gastrointestinal nematodes. BMC Genomics 7, 42.

Kerr, M.K., Churchill, G.A., 2001. Experimental design for gene expression microarrays. Biostatistics 2, 183-201.

Kerr, M.K., Martin, M., Churchill, G.A., 2000. Analysis of variance for gene expression microarray data. J. Comput. Biol. 7, 819-837.

Li, R.W., Sonstegard, T.S., Van Tassell, C.P., Gasbarre, L.C., 2007. Local inflammation as a possible mechanism of resistance to gastrointestinal nematodes in Angus heifers. Vet. Parasitol. 145, 100-107.

Lillard, J.W., Boyaka, P.N., Taub, D.D., McGhee, J.R., 2001. RANTES potentiates antigen-specific mucosal immune responses. J. Immunol. 166, 162-169.

Malczewski, A., Jolley, W.R., Woodard, L.F., 1996. Prevalence and epidemiology of trichostrongylids in Wyoming cattle with consideration of the inhibited development of Ostertagia ostertagi. Vet. Parasitol. 64, 285-297.

Michel, J.F., 1967. Regulation of egg output of populations of Ostertagia ostertagi. Nature 215, 1001-1002.

Michel, J.F., Lancaster, M.B., Hong, C., 1972. Host induced effects on the vulval flap of Ostertagia ostertagi. Int. J. Parasitol. 2, 305-317.

Muhle, R.A., Pavlidis, P., Grundy, W.N., Hirsch, E., 2001. A high-throughput study of gene expression in preterm labor with a subtractive microarray approach. Am. J. Obstet. Gynecol. 185, 716-724.

Newton, M.A., Kendziorski, C.M., Richmond, C.S., Blattner, F.R., Tsui, K.W., 2001. On differential variability of expression ratios: improving statistical inference about gene expression changes from microarray data. J. Comput. Biol. 8, 37-52.

Nielsen, C.H., Leslie, R.G.Q., 2002. Complement's participation in acquired immunity. J. Leukoc. Biol. 72, 249-261.

Pan, W., Lin, J., Le, C.T., 2002. How many replicates of arrays are required to detect gene expression changes in microarray experiments? A mixture model approach. Genome Biol. 3, 1-10.

Pernthaner, A., Stankiewicz, M., Cabaj, W., Pfeffer, A., Green, R.S., Douch, P.G., 1996. Immune responsiveness of nematode-resistant or suscep- tible Romney line-bred sheep to continuous infection with Trichostrongylus axei. Vet. Immunol. Immunopathol. 51, 137-146.

SAS Institute Inc., 2000. SAS/STAT Software Version 8. SAS Institute, Inc. Cary, NC.

Sigma Genosis, 2000. Panorama Human Cytokine Gene Arrays. Analysis of Gene Expression During Cellular Responses to Developmental Cues, Physicological or Pathological Conditions, or External Stimuli. Sigma Genosis.

Smith, T.P.L., Grosse, W.M., Freking, B.A., Roberts, A.J., Stone, R.T., Casa, E., Wray, J.E., White, J., Cho, J., Fahrenkrug, S.C., Bennet, G.L., Heaton, M.P., Laegreid, W.W., Rohrer, G.A., Chitko-McKown, C.G., Pertea, G., Holt, I., Karamycheva, S., Liang, F., Quackenbush, J., Keele, J.W., 2001. Sequence evaluation of four pooled-tissue normalized bovine cDNA libraries and construction of a gene index for cattle. Genome Res. 11, 626-630.

Sonstegard, T.S., Gasbarre, L.C., 2001. Genomics tools to improve parasite resistance. Vet. Parasitol. 101, 387-403.

Sonstegard, T.S., Capuco, A.V., White, J., Van Tassell, C.P., Connor, E.E., Cho, J., Sultana, R., Shade, L., Wray, J.E., Wells, K.D., Quackenbush, J., 2002. Analysis of bovine mammary gland EST and functional annotation of the Bos taurus gene index. Mamm. Genome 13, 373-379.

Stevenson, L.M., Colditz, I.G., LeJambre, L.F., 2001. Expression of cell surface adhesion molecules by peripheral blood eosinophils during Trichostrongylus colubriformis infection in sheep. Immunol. Cell Biol. 79, 240-244.

Urban Jr., J.F., Madden, K.B., Svetic, A., 1992. The importance of Th2 cytokines in protective immunity to nematodes. Immunol. Rev. 127, 205-220.

Vercruysse, J., Claerebout, E., 1997. Immunity development against Ostertagia ostertagi and other gastrointestinal nematodes in cattle. Vet. Parasitol. 72, 309-326.

Williams, J.C., 1997. Anthelmintic treatment strategies: current status and future. Vet. Parasitol. 72, 461-477.

Wolfinger, R.D., Gibson, G., Wolfinger, E.D., Bennett, L., Hamadeh, H. Bushel, P., Afshari, C., Paules, R.S., 2001. Assessing gene significance from cDNA microarray expression data via mixed models. J. Comput. Biol. 8, 625-637.

Zarlenga, D.S., Canals, A., Aschenbrenner, R.A., Gasbarre, L.C., 1995. Enzymatic amplification and molecular cloning of cDNA encoding the small and large subunits of bovine interleukin 12. Biochim. Biophys. Acta 1270, 215-217. 